\title{
Kathy Fan appointed to KCL chair as UK's first female Professor of OMFS
}

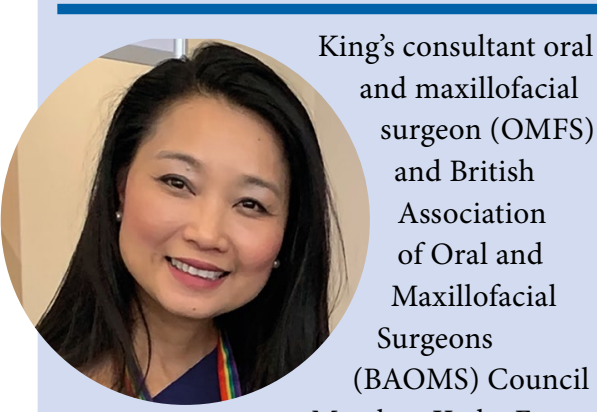

Member, Kathy Fan

has been appointed Professor of Oral and Maxillofacial Surgery by King's College London (KCL). She is the first duallyqualified (medical and dental) female maxillofacial surgeon to be awarded this honour.

Professor Fan said she was thrilled: 'The award of my Chair is important recognition for my specialty, my work in the NHS, the university, nationally and internationally. But the most significant aspect of my appointment as the first female Professor with an FRCS (OMFS) is to show younger OMFS surgeons that everything is possible.

She told OMFS trainees and younger surgeons that diversity in surgery and academia is important: Female surgeons, surgeons of different ethnic and orientation

'You can do it'! Do not to let your ambitions be limited by perceptions or prejudice. I believe the principle of 'if you can see it, you can be it' is very important. This is the essence behind the BAOMS Wall of Diversity.'

She added that throughout her career she has had the support of her 'family, colleagues - and the supportive BAOMS specialty family'.

Congratulating Professor Fan, BAOMS President Austen Smith said: 'To become a Professor in Oral and Maxillofacial Surgery with dual medical and dental qualification, and an FRCS (OMFS), requires many years of clinical, academic and teaching activity. In the UK, there are less than a dozen Professors of OMFS, and until Kathy Fan was awarded her KCL Chair, this group was all male - and, this is a first for our specialty in the UK.'

He applauded Professor Fan's commitment as a member of the BAOMS Council, adding: 'She is dedicated to supporting the doctors undertaking their KCL three-year Dentistry Programme of Medical Graduates and the dentists studying medicine, guiding them into specialty training.

'The specialty owes her a debt of gratitude for making KCL a hot-spot for OMFS recruitment and research. That KCL has recognised her excellence by awarding her a Professorship is just fantastic.

'I want this to be an inspiration to all OMFS trainees of every gender, race and ethnic background.'

Modern UK OMFS training requires dental and medical degrees, completing core surgical training and passing the Royal Colleges of Surgeons membership exam. This is followed by at least five years specialty training that culminates in the Fellowship of the Royal Colleges of Surgeons (FRCS OMFS) for entry onto the OMFS specialist list. Academic OMFS surgeons do all of this and complete a higher degree, such as a $\mathrm{PhD}$ that requires at least three years of research.

Announcing the KCL 2020-2021 academic promotions, Professor Mike Curtis, Executive Dean for the Faculty of Dentistry, Oral \& Craniofacial Sciences, said: 'Kathy's appointment is very well deserved.'

\section{Budget leaves NHS dentistry in last chance saloon}

The British Dental Association has lamented the budget's failure to recognise the challenges facing dental services across England. It follows calls from both the BDA and Healthwatch England to provide vital funding for the recovery and rebuild of services, which was backed recently by over 40 cross-party MPs.

Reform of the widely discredited model the service operates to was pledged by April 2022. Dentist leaders have expressed disbelief that no commitments have been made to provide the necessary resources to deal with the backlogs and underpin a transition to a new and sustainable model of care.

Over 35 million appointments have been lost in England since lockdown, and even before COVID-19 funding was sufficient to cover barely half the population.

The BDA had joined with public health leaders in early October for reversal of savage cuts to local public health budgets. There is no indication the Treasury appears willing to change tack.

The 50\% business rates discount extended to the retail and hospitality sectors once again leaves high street dentists as among the only businesses on the high street not receiving needed support.

British Dental Association Chair Eddie Crouch said: 'MPs have recognised NHS dentistry is in

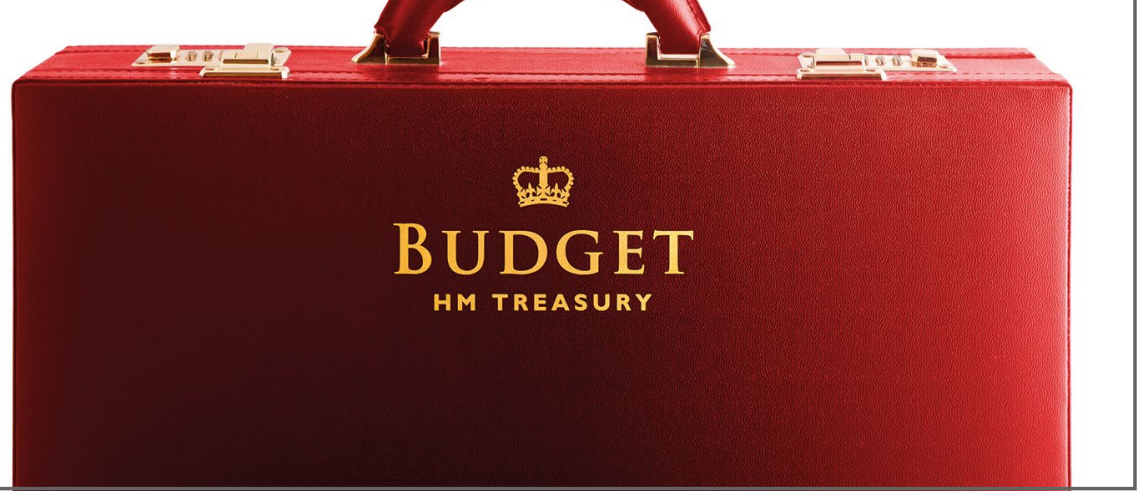

the last chance saloon.

'Sadly the Chancellor has offered this service no help clearing the backlogs, no support for the rebuild and recovery, and no boost for public health.

'COVID-19 busted an already failed system, but any reform plan is doomed without new investment. Any credible

'levelling up' agenda cannot ignore millions of patients with no hope of securing needed care.' 